\title{
Isolated Primary Neurofibroma of Small Intestine: Presenting as Acute Intestinal Obstruction
}

\author{
Keyur S Bhatt, Vijay Kanani, KG Naik \\ Department of HPB \& GI surgery, SIDS Hospital, Ring Road, Surat, Gujarat, India.
}

\author{
Corresponding Author: \\ Dr. Keyur Bhatt \\ Email: drkeyurbhatt@gmail.com \\ This is an Open Access article distributed \\ under the terms of the Creative Commons \\ Attribution License (creativecommons.org/ \\ licenses/by/3.0). \\ Received \\ Accepted \\ November 14, 2016 \\ Published \\ January 19, 2017 \\ February 15, 2017
}

\begin{abstract}
Background: Neurofibromas of the small bowel are rare and usually are part of the involvement in neurofibromatosis type 1 (Nf1, von Recklinghausen's disease). Solitary neurofibromas of the small bowel are extremely rare. Case Report: We describe a case of an isolated neurofibroma originating in small bowel of a patient who presented to us with recurrent sub-acute intestinal obstruction. Conclusion: Presentation of isolated neurofibroma of small intestine as acute obstruction is rare and preoperative diagnosis is difficult.
\end{abstract}

Keywords: Humans, Intestinal Obstruction, Nerve Sheath Neoplasms, Neurofibroma, Neurofibromatoses.

\section{Introduction}

Neurofibromas exist rarely in the small bowel as isolated neoplasm outside the classical clinical picture of von Recklinghausen's disease (neurofibromatosis type 1, Nf1). Intestinal neurofibromatosis is characterized by multiple neurofibromas usually in the small intestine and stomach; may rarely present as a sporadic case in a patient without features of the generalized neurofibromatosis. Isolated small intestinal neurofibromatosis is even more unusually described in the literature $[1,2]$. Here we describe a rare case of isolated solitary small intestinal neurofibroma in a patient without features of Nf1.

\section{Case Report}

A 45 year old female presented with complaints of colicky lower abdominal pain associated with lower abdominal distension and nausea. She had three similar episodes in last six months. General physical examination carried out did not show any significant findings. Clinically the patient had no café-au-lait spots, axillary freckling, peripheral neurofibromas or pigmented hamartomas of the iris. There was no family history of neurofibromatosis.

Abdomen was distended, non-tender, soft, without any visceromegaly or free fluid but bowel sounds were hyper-peristaltic. Patient was admitted in hospital, laboratory investigations including complete blood count, serum electrolytes, renal function tests, liver function tests and coagulation tests were within normal limits. Ultrasound abdomen suggested ileo-ileal intussusception with dilated proximal small bowel loops with two hypo-echoic lesions around $2 \times 3 \mathrm{~cm}$ in size, as a lead point, plus mesenteric lymphadenopathy, rest of the abdominal viscera were normal. CECT of abdomen suggested ileo-ileal intussusception with two non-enhancing hypodense lesions in ileum as a lead point, proximal small bowel dilation, suggestive of intestinal obstruction, few enlarged mesenteric lymph nodes, and no free fluid [Fig.1].

Surgery was performed with lower midline laparotomy and similar findings were noted. Intussusception was reduced and affected portion of small bowel including the lesions was resected 
along with one of the mesenteric lymph node and sent for histological examination [Fig.2], and intestinal continuity was restored with ileoileal anastomosis, and abdomen closed. Two pedenculated, firm lesions of $3 \times 3 \mathrm{~cm}$ size were sent for histopathology from ileum. Cut surface of specimen was of snow white color with normal surrounding ileal mucosa. Recovery of the patient was uneventful and discharged on post-operative day five with normal diet, without any complication.

Histopathology was suggestive of benign spindle cell neurofibroma arising from submucosa of small intestine having pale eosinophilic cytoplasm and vesicular elongated nuclei. There was no evidence of increased mitotic activity, hemorrhage or necrosis. Lymph nodes showed reactive changes. Immunohistology blocks were negative for CD 117 (c-kit), smooth muscle actin and positive staining for S100P.

\section{Discussion}

Neurofibromas are usually manifestations of the von Recklinghausen's disease. They are benign neoplasms consisting of neural and connective tissue components like schwann and perineural cells and myofibroblasts. They are usually multiple on presentation and are part of a hereditary disorder with two clinical forms: Nf1 (or von Recklinghausen's neurofibromatosis or peripheral neurofibromatosis, Nf1) and neurofibromatosis type 2 (or central neurofibromatosis or bilateral acoustic neurofibromatosis). These disease entities have variable clinical expressions with manifestations involving the skin, nervous system, eyes, bones, gastrointestinal tract, and other body parts. There is also a disease type called segmental neurofibromatosis, which involves a specific body organ without the variety of multiple pathologic expressions of the generalized form. Neurofibromas may be cutaneous, nodular derived from peripheral nerves or plexiform with aggressive, infiltrative growth that extends outside the nerve sheath to the surrounding tissue. Although benign, neurofibromas of the nodular and particular the

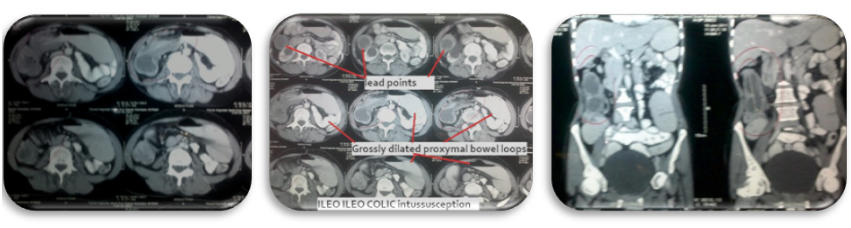

Fig.1: CECT of abdomen suggestive of ileao-ileal intussusception with gross proximal dilation of intestinal loops with two hypo-echoic lesions as a lead point.
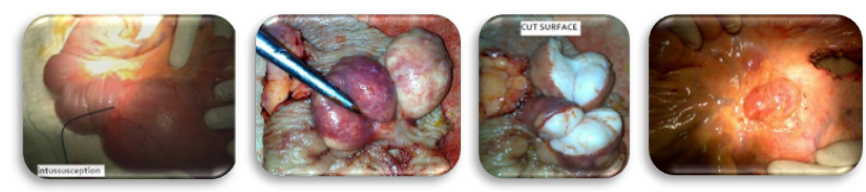

Fig.2(a): Intra-operative picture suggestive of ileo-ileal intussusception, (b): Resected small bowel with two soft tissue lesions, (c): Cut surface of lesion, (d): Enlarged mesenteric lymph node.

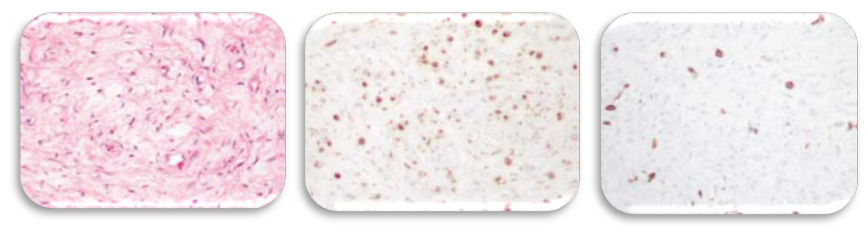

Fig.3(a): $H \&$ \& stain of neurofibroma, (b): IHC for S100P positive staining, (c): IHC For c-kit suggesting scanty staining of mast cells and non-staining of tumor cells.

plexiform type may demonstrate a malignant transformation in 2-16\% of affected individuals [1-4]. About $50 \%$ of the cases of Nf1 are not familial but sporadic as a result of germ-cell mutations.

Participation of the gastrointestinal tract has been documented in $25 \%$ of patients with Nf1. Characteristic neurofibromas have been found in the digestive tract in $11 \%$ of patients with Nf1 [5]. Intestinal neurofibromatosis exists, in the majority of cases, in association with Nf1 and only rarely presents outside this disease as a separate pathologic entity (familial or sporadic) [2]. Multiple neurofibromas are discovered in the gut, more often located in the jejunum, stomach, ileum, duodenum, and colon according to the frequency of their appearance $[1,5]$. Neurofibromas usually originate from either the plexus of Meissner in the submucosa or the plexus of Auerbach's in the muscularis propria or even from the serosa $[2,6]$. 
The lesions are often sessile and wide based but also pedunculated polyps have been observed [2]. These lesions most often are discovered in the $4^{\text {th }}-6^{\text {th }}$ decade of life [7-9]. It is common to remain clinically silent and rarely cause symptoms before puberty. The clinical picture includes abdominal pain, palpable masses, hemorrhage due to necrosis or ulceration of the mucosa, obstruction due to intussusception or extraluminar pressure, perforation, megacolon, peptic ulcer disease, diarrhea, steatorrhea, obstructive jaundice and obstruction of the pancreatic tract. $[2,5,10]$. Isolated colonic neurofibromatosis without other features suggestive of $\mathrm{Nfl}$ has been very rarely encountered in the clinical practice. Few cases of isolated colonic neurofibromatosis with no evidence of Nfl have been documented in the literature $[2,11]$. Isolated neurofibroma have been reported from gastrointestinal tract include soft palate, esophagus, ileum, common bile duct, gall bladder, and anal canal [11-17].

\section{Conclusion}

Isolated neurofibroma of small intestine are generally asymptomatic but can occasionally present as acute intestinal obstruction. Surgical excision with resection and anastomosis of the bowel may be required.

Contributors: KSB, VK: manuscript writing and case management; KGN: histopathology and critical review of manuscript. KSB will act as guarantor. All authors approved the final version of manuscript.

Funding: None; Competing interests: None stated.

\section{References}

1. Reynolds RM, Browning GG, Nawroz I, Campbell IW. Von Recklinghausen's neurofibromatosis: neurofibromatosis type 1. Lancet. 2003;361:1552-1554.

2. Bononi M, De Cesare A, Stella MC, Fiori E, Galati G, Atella F, et al. Isolated intestinal neurofibromatosis of colon. Single case report and review of the literature. Dig Liver Dis. 2000;32:737-742.

3. Kim HR, Kim YJ. Neurofibromatosis of the colon and rectum combined with other manifestations of von
Recklinghausen's disease: report of a case. Dis Colon Rectum. 1998;41:1187-1192.

4. Hirsch NP, Murphy A, Radcliffe JJ. Neurofibromatosis: clinical presentations and anaesthetic implications. $\mathrm{Br} \mathrm{J}$ Anaesth. 2001;86:555-564.

5. Pinsk I, Dukhno O, Ovnat A, Levy I. Gastrointestinal complications of von Recklinghausen's disease: two case reports and a review of the literature. Scand J Gastroenterol. 2003;38:1275-1278.

6. Jacob S, Prabhakar BR, Singh SK, Mammen KJ. Neurofibromatosis of the colon: an unusual manifestation of von Recklinghausen's diseases-a case report. Indian J Pathol Microbiol. 1998;41:113-116.

7. Gogus S, Sarikayalar F, Akcoren Z, Yalnizoglu D, Hicsonmez A. Intestinal involvement and vasculopathy in von Recklinghausen's neurofibromatosis. Turk J Pediatr. 1997;39:117-122.

8. Jacob S, Prabhakar BR, Singh SK, Mammen KJ. Neurofibromatosis of the colon: an unusual manifestation of von Recklinghausen's diseases-a case report. Indian J Pathol Microbiol. 1998;41:113-116.

9. Giuly JA, Picand R, Giuly D, Monges B, Nguyen-Cat R. Von Recklinghausen disease and gastrointestinal stromal tumors. Am J Surg. 2003; 185:86-87.

10. Abramson LP, Orkin BA, Schwartz AM. Isolated colonic neurofibroma manifested by massive lower gastrointestinal bleeding and intussusception. South Med J. 1997;90:952-954.

11. Magro G, Piana M, Venti C, Lacagnina A, Ruggieri M. Solitary neurofibroma of the mesentery: report of a case and review of the literature. Pathol Res Pract. 2000;196:713-718.

12. Frick EJ Jr, Lapos L, Vargas HD. Solitary neurofibroma of the anal canal: report of two cases. Dis Colon Rectum. 2000;43:109-112.

13. Saitoh K, Nasu M, Kamiyama R, Hatakeyama S, Maruyama M, Tsuruta K, Takeshita K. Solitary neurofibroma of the esophagus. Acta Pathol Jpn. 1985;35:527-531.

14. Sinha R, Paul R, Sen I, Sikdar B. A solitary huge neurofibroma of the soft palate. J Laryngol Otol. 2002;116:637-638.

15. Acebo E, Fernandez FA, Val-Bernal JF. Solitary neurofibroma of the gallbladder. A case report and review of the literature. Gen Diagn Pathol. 1998;143:337-340.

16. Carbia S, Pagola J, Flaster N, Guida A, Jufe L, Gonzalez $\mathrm{B}$, Caniparoli A. Isolated neurofibroma of the common bile duct. Medicina. 1995;55:689-692.

17. Kostakopoulos A, Chorti M, Protogerou V, Kokkinou S. Solitary neurofibroma of kidney: clinical, histological and chromosomal appearance. Int Urol Nephrol. 2003;35:11-13. 